\title{
Separation of acid blue 25 from aqueous solution using water lettuce and agro-wastes by batch adsorption studies
}

\author{
Muhammad Raziq Rahimi Kooh ${ }^{1}$ (1) Muhammad Khairud Dahri ${ }^{1}$. Linda B. L. Lim ${ }^{1}$ - Lee Hoon Lim ${ }^{1} \cdot$ Chin Mei Chan $^{1}$
}

Received: 7 November 2017 / Accepted: 11 April 2018 / Published online: 20 April 2018

(c) The Author(s) 2018

\begin{abstract}
Three plant-based materials, namely water lettuce (WL), tarap peel (TP) and cempedak peel (CP), were used to investigate their potentials as adsorbents using acid blue 25 (AB25) dye as a model for acidic dye. The adsorbents were characterised using Fourier transform infrared spectroscopy, X-ray fluorescence and scanning electron microscope. Batch experiments involving parameters such as $\mathrm{pH}$, temperature, contact time, and initial dye concentration were done to investigate the optimal conditions for the adsorption of AB25 onto the adsorbents. Thermodynamics study showed that the uptake of AB25 by the three adsorbents was feasible and endothermic in nature. Both the Langmuir and Freundlich isotherm models can be used to describe the adsorption process of $\mathrm{AB} 25$ onto $\mathrm{WL}$ and $\mathrm{CP}$ while pseudo-second-order fitted the kinetics data, suggesting that chemisorptions were majorly involved. The use of $0.1 \mathrm{M}$ of $\mathrm{NaOH}$ showed the best results in regenerating of the WL, TP and CP's adsorption ability after AB25 treatment.
\end{abstract}

Keywords Acid blue $25 \cdot$ Adsorption · Artocarpus odoratissimus · Artocarpus integer $\cdot$ Pistia stratiotes $\cdot$ Water remediation

\section{Introduction}

One of the basic necessities of every living organism is water and on Earth, the water sources come from seawater (96.5\%) and freshwater $(2.5 \%)$ such as river, glacier and lakes. Of these two sources, only freshwater is suitable for human use as seawater has high salinity. Unfortunately, the usable water source is not infinite and the usage of this water grows as the human population grows which brings problems as industrialisation increases to provide for the population need. The

Muhammad Raziq Rahimi Kooh

chernyuan@hotmail.com

Muhammad Khairud Dahri

kiddri86@hotmail.com

Linda B. L. Lim

linda.lim@ubd.edu.bn

Lee Hoon Lim

leehoon.lim@ubd.edu.bn

Chin Mei Chan

chinmei.chan@ubd.edu.bn

1 Faculty of Science, Universiti Brunei Darussalam, Jalan Tungku Link, Pengkalan Gadong,

Bandar Seri Begawan BE 1410, Brunei Darussalam industrial discharge to the water bodies is a major concern to both human and other living things as it directly affects their health and food sources.

Synthetic dye is one of the industrial discharges which is non-biodegradable, potentially carcinogenic and mutagenic. This coloured compound, even in low concentration, is highly visible if it is present in the water bodies causing unaesthetic view. Therefore, it is imperative that dye wastewater is remediated before discharging into the environment. Various methods of treating the dye wastewater have been researched and they are discussed in the literature (Robinson et al. 2001).

One of the wastewater treatment methods discussed is adsorption; a simple method that utilises a variety of materials such as leaf (Kooh et al. 2017a, b), bacteria (Pearce et al. 2003), fungi biomass (Fu and Viraraghavan 2001) and agriculture wastes (Crini 2006) as adsorbents. This method adopts the concept of adhering the pollutant onto the adsorbent which is not only simple but also does not produce any harmful by-products from chemical reactions. Another attractive feature of adsorption is its simple procedural design and the overall cost is relatively low.

This study aims to investigate the performance of water lettuce (WL), tarap (Artocarpus odoratissimus) peel (TP) 
and cempedak (Artocarpus integer) peel (CP) in removing the anionic dye acid blue 25 (AB25) from aqueous solution. $\mathrm{AB} 25$ is chosen as it has wide applications in cosmetic, fabric and aluminium finishing and can serve as a model anionic dye compound. The objectives of this study include the various characterisations of the adsorbents, investigation of the effects of initial dye concentration, $\mathrm{pH}$, contact time, and also thermodynamics and regeneration experiments.

WL is scientifically known as Pistia stratiotes and it is mainly found in tropical and subtropical regions around the world. It is usually found to choke drain and water channel, and thrive in water with minimal nutrients. The proliferative growth leads to formation of dense mat on the surface of water, reducing sunlight penetration into the water, and is associated with decreased dissolved oxygen content. The high-proliferative growth behaviour with minimal input and attention makes WL an attractive adsorbent. Tarap and cempedak belong to the same genus Artocarpus, and they are vastly available in Southeast Asia (Tang et al. 2013). The sweet edible pulp is consumed, while large portion of the thick rind is usually discarded and hence it is utilised as an adsorbent. Previous study on the use of water lettuce to remove a triphenylmethane dye (methyl violet) from aqueous solution has been reported (Lim et al. 2016) and the Artocarpus spp. were used in adsorption studies to remove methylene blue, cadmium and copper (Kooh et al. 2016a, b; Lim et al. 2012, 2015, 2017; Priyantha et al. 2013), showing their potentials as adsorbent to remove basic dyes and heavy metals.

\section{Materials and methods}

\section{Preparation of adsorbents and adsorbate}

Water lettuce (WL) was collected from a choked drain in the Rimba Horticulture Centre, Brunei-Muara district, Brunei Darussalam, while tarap and cempedak fruits, sold in local markets, were randomly selected and purchased. The peels were separated from the fruit. After washing all the three samples with distilled water, they were then dried in an oven at $70{ }^{\circ} \mathrm{C}$. The dried adsorbents were then blended, sieved and kept in desiccators.

AB25 $\left(\mathrm{C}_{20} \mathrm{H}_{13} \mathrm{~N}_{2} \mathrm{NaO}_{5} \mathrm{~S}, \mathrm{M}_{\mathrm{r}} 416.38 \mathrm{~g} \mathrm{~mol}^{-1}, 45 \%\right.$ dye purity, Sigma-Aldrich) was used as received.

\section{Characterisation of adsorbents}

The adsorbents were characterised using an X-ray fluorescence (XRF) spectrophotometer (PANalytical Axios ${ }^{\max }$ ) for the elemental analyses, a Fourier transform infrared (FTIR) spectrophotometer (Shimadzu Model IRPrestige-21 spectrophotometer) for functional group analyses and a scanning electron microscope (SEM) (Tescan Vega XMU) for the surface morphology analyses. The point of zero charge $\left(\mathrm{pH}_{\mathrm{pzc}}\right)$ of the adsorbents was determined by the salt addition method using $0.1 \mathrm{~mol} \mathrm{~L}^{-1} \mathrm{KNO}_{3}$ solutions following procedures from the literature (Zehra et al. 2015).

\section{Batch adsorption procedures}

The adsorption experiment was performed by agitating $0.04 \mathrm{~g}$ adsorbent with $20 \mathrm{~mL}$ dye solution in $100-\mathrm{mL}$ conical flasks at the speed of $250 \mathrm{rpm}$ using a Stuart orbital shaker. The filtrate was analysed using a UV-visible spectrophotometer (Shimadzu UV-1601PC) at wavelength of $597 \mathrm{~nm}$.

To evaluate the performance of the adsorbent in the removal of dye, adsorption capacity $q_{\mathrm{e}}\left(\mathrm{mg} \mathrm{g}^{-1}\right)$ and the percentage removal were calculated, and the equations are as follows:

$q_{\mathrm{e}}=\frac{\left(C_{\mathrm{i}}-C_{\mathrm{e}}\right) V}{m}$,

$\%$ removal $=\frac{\left(C_{\mathrm{i}}-C_{\mathrm{e}}\right) \times 100 \%}{C_{\mathrm{i}}}$,

where $C_{\mathrm{i}}$ is the initial adsorbate concentration $\left(\mathrm{mg} \mathrm{L}^{-1}\right), C_{\mathrm{e}}$ is the concentration of adsorbate left in the solution after equilibrium $\left(\mathrm{mg} \mathrm{L}^{-1}\right), V$ is the volume of adsorbate solution (L) and $m$ is the mass of adsorbent (g).

The parameters included in this study are the effects of contact time (5-240 min), $\mathrm{pH}(2-10)$ and initial AB25 concentrations (20-500 $\mathrm{mg} \mathrm{L}^{-1}$ ), with the change of one parameter at a time while keeping the rest constant.

There are many models that have been used for characterising the adsorption process. Data from the effect of initial dye concentration were fitted into three adsorption isotherm models (Langmuir, Freundlich and Dubinin-Radushkevich models) while the data from effect of contact time were fitted into three kinetics models (pseudo-first-order, pseudosecond-order and intraparticle diffusion models). The best models that described the adsorption data were determined by looking at the values of the $R^{2}$ and two error functions which are the sum of absolute error (EABS) and Chi-square test $\left(\chi^{2}\right)$ as shown in Eqs. (3) and (4), respectively:

EABS: $\sum_{i=1}^{n}\left|q_{\mathrm{e}, \mathrm{exp}}-q_{\mathrm{e}, \mathrm{cal}}\right|$,

$\chi^{2}: \sum_{i=1}^{n} \frac{\left(q_{\mathrm{e}, \exp }-q_{\mathrm{e}, \mathrm{cal}}\right)^{2}}{q_{\mathrm{e}, \exp }}$

where $q_{\mathrm{e}, \mathrm{exp}}$ is the experimental data while $q_{\mathrm{e}, \mathrm{cal}}$ is the calculated data from the isotherm or kinetics model. 


\section{Thermodynamics experiments}

The Van't Hoff equation was used for determining the thermodynamics nature of the adsorption process and the equations are as follows:

$\Delta G^{\circ}=\Delta H^{\circ}-T \Delta S^{\circ}$,

$\Delta G^{\circ}=-R T \ln k$,

$k=\frac{C_{\mathrm{s}}}{C_{\mathrm{e}}}$

$\ln k=\frac{\Delta S^{\circ}}{R}-\frac{\Delta H^{\circ}}{R T}$,

where $\Delta G^{\circ}\left(\mathrm{kJ} \mathrm{mol}^{-1}\right)$ is the Gibbs free energy, $\Delta H^{\circ}$ $\left(\mathrm{kJ} \mathrm{mol}^{-1}\right)$ is the change in enthalpy, $\Delta S^{\circ}\left(\mathrm{J} \mathrm{mol}^{-1} \mathrm{~K}^{-1}\right)$ is the change in entropy, $T(\mathrm{~K})$ is the temperature, $k$ is the distribution coefficient for adsorption, $C_{\mathrm{s}}\left(\mathrm{mg} \mathrm{L}^{-1}\right)$ is the concentration of AB25 adsorbed on the adsorbent at equilibrium and $R$ is the gas constant $\left(8.314 \mathrm{~J} \mathrm{~mol}^{-1} \mathrm{~K}^{-1}\right)$.

The adsorption experiment was carried out at five different temperatures $\left(25,40,50,60\right.$ and $\left.70{ }^{\circ} \mathrm{C}\right)$ using $20 \mathrm{~mL}$ of $50 \mathrm{mg} \mathrm{L}^{-1} \mathrm{AB} 25$ at solution $\mathrm{pH}$ of 2.0. The thermodynamics parameter $\Delta G^{\circ}$ was calculated using Eq. (6), while $\Delta H^{\circ}$ and $\Delta S^{\circ}$ were calculated from the linear plot of $\ln k$ vs $T^{-1}$ of Eq. (8).

\section{Regeneration experiments}

The detailed procedures of the regeneration experiment were described in our previous work (Dahri et al. 2014). In short, the spent adsorbents were prepared using $20 \mathrm{~mL}$ of $50 \mathrm{mg} \mathrm{L}^{-1} \mathrm{AB} 25$ and regenerated using distilled water, $0.1 \mathrm{~mol} \mathrm{~L}^{-1} \mathrm{HNO}_{3}$ and $0.1 \mathrm{~mol} \mathrm{~L}^{-1} \mathrm{NaOH}$. The regeneration experiments were carried out for five cycles.

\section{Results and discussion}

\section{Characterisations of adsorbents}

Characterisations of the adsorbents are important as they provide much useful information regarding the adsorbents. The elemental analyses of adsorbents are summarised in Table 1, which provide the information regarding the micromineral and macro-mineral contents.

Molecules such as hydroxyl and carbonyl groups contain dipole moment which can absorb infrared radiation at specific frequencies and is characteristic for each functional group (Pavia et al. 1996). This makes FTIR analysis to be very useful in the characterisation of functional groups
Table 1 XRF elemental analyses of WL, TP and CP

\begin{tabular}{lcll}
\hline \multicolumn{4}{l}{ Normalised percentage $(\%)$} \\
\hline Element & WL & TP & CP \\
\hline $\mathrm{Mn}$ & 0.41 & 0.57 & 0.82 \\
$\mathrm{Al}$ & 0.55 & 0.18 & 0.19 \\
$\mathrm{Si}$ & 1.21 & 1.46 & 2.05 \\
$\mathrm{Mg}$ & 1.45 & 1.75 & 2.13 \\
$\mathrm{Na}$ & 1.55 & $\mathrm{ND}$ & $\mathrm{ND}$ \\
$\mathrm{S}$ & 1.59 & 1.89 & 1.89 \\
$\mathrm{P}$ & 1.79 & 1.88 & 0.75 \\
$\mathrm{Cl}$ & 18.30 & 3.07 & 0.13 \\
$\mathrm{Ca}$ & 19.70 & 3.49 & 9.60 \\
$\mathrm{O}$ & 22.80 & 26.60 & 28.50 \\
$\mathrm{~K}$ & 28.70 & 38.00 & 28.70 \\
\hline
\end{tabular}

present in an adsorbent. Figure 1 shows the FTIR spectra for WL, TP and CP before AB25 treatment. In general, hydroxyl and/or amino group can be found at the stretching band of around $3300-3400 \mathrm{~cm}^{-1}$. Band at around $2900 \mathrm{~cm}^{-1}$ indicates the $\mathrm{C}-\mathrm{H}$ bond stretching while $\mathrm{N}-\mathrm{H}$ bending $\left(1630 \mathrm{~cm}^{-1}\right)$, phenyl $\left(1413 \mathrm{~cm}^{-1}\right)$ and $\mathrm{C}-\mathrm{O}-\mathrm{C}\left(1022 \mathrm{~cm}^{-1}\right)$ can be found at around 1610, 1400 and $1060 \mathrm{~cm}^{-1}$, respectively. After AB25 treatment as shown in Fig. 1b, it can be observed that there is a significant shift in stretching band for $\mathrm{OH}$ and $\mathrm{NH}$ groups as well as NH bending band. Hence, these functional groups could be involved in AB25 adsorption onto the adsorbents' surfaces.

The surface morphology analyses of the WL, TP and CP are shown in Fig. 2, which provide visual insights into the surface of adsorbent particles. Both WL and CP have rough and uneven surface while TP has smoother looking surface. All the adsorbents did not have any orderly pattern.

\section{Study of pH medium}

The electrostatic interactions between the adsorbent's surface and the dye are directly affected by $\mathrm{pH}$, thus making it important to investigate the effect of $\mathrm{pH}$. The $\mathrm{pH}_{\mathrm{pzc}}$ is a point where the net charge on the surface of the adsorbent is zero. When solution $\mathrm{pH}>\mathrm{pH}_{\mathrm{pzz}}$, the adsorbent's surface is predominant negatively charged, while $\mathrm{pH}<\mathrm{pH}_{\mathrm{pzc}}$ resulted in predominantly positively charged surface. $\mathrm{The}_{\mathrm{pH}}$ of WL and CP was determined to be 6.40 and 4.01 , respectively, while for TP was determined as 4.40 in previous work (Lim et al. 2015). Figure 3 indicates that as the solution $\mathrm{pH}$ decreased, the dye removal gradually increased for the all three adsorbents (WL, CP and TP). The optimum $\mathrm{pH}$ was observed to be at $\mathrm{pH} 2.0$ for all three adsorbents. This behaviour is explained with the concept of $\mathrm{pH}_{\mathrm{pzc}}$, where at $\mathrm{pH} 2$, the anionic AB25 dye molecules are attracted to the predominant positively charged surface and this observation 
Fig. 1 FTIR spectra of a WL, b TP, c CP, d WL-AB25, e $\mathrm{TP}-\mathrm{AB} 25$ and $\mathbf{f} \mathrm{CP}-\mathrm{AB} 25$
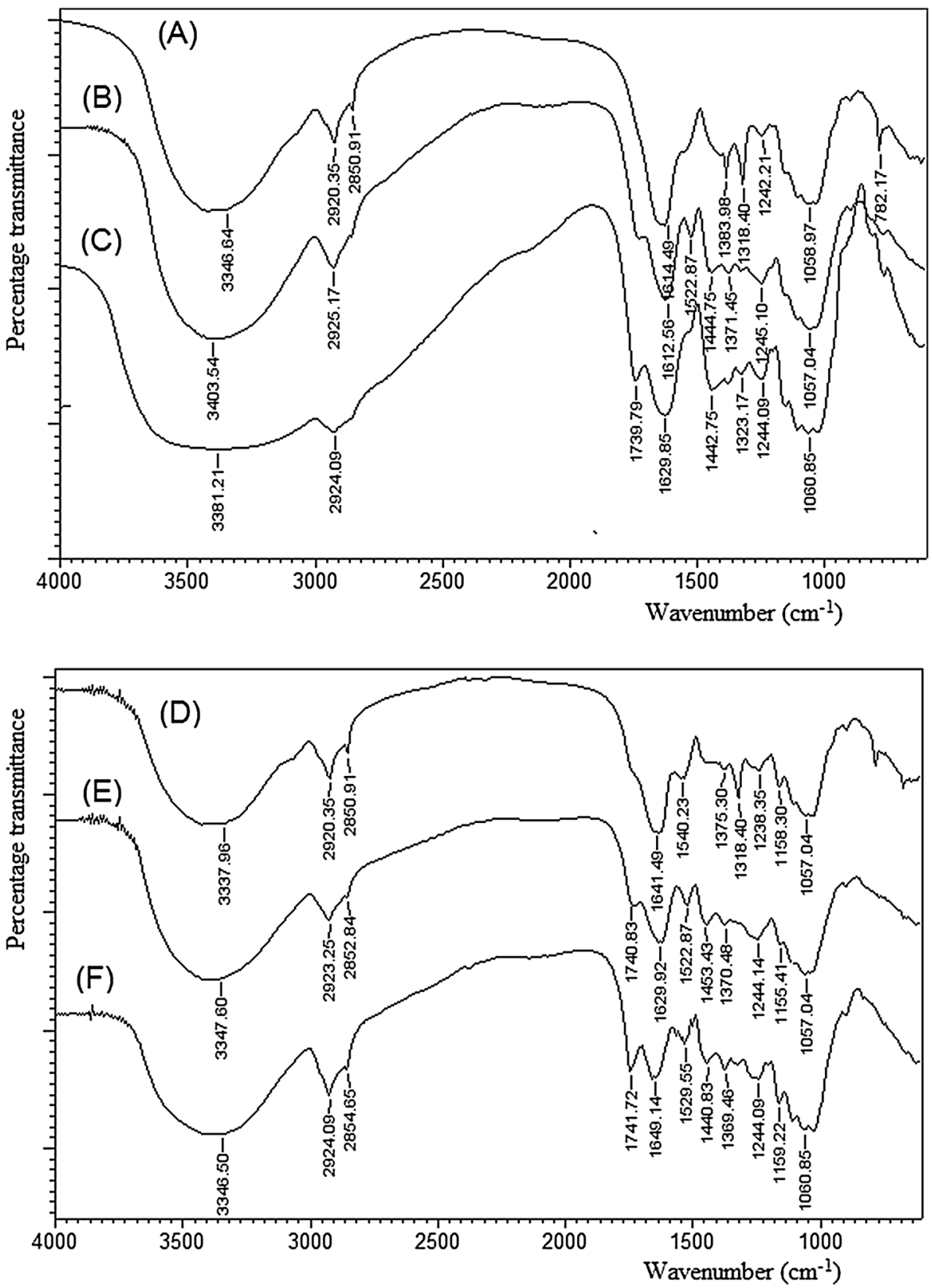

suggests that the adsorption of AB25 onto these adsorbents depends mainly on ionic interaction.

\section{Effect of contact time and kinetics modelling}

The effect of contact time is important in adsorption study as vital information such as the time required for adsorption process to attain complete equilibrium can be obtained. The data of the effect of contact time are summarised in Fig. 4.

The observed trend for all the three adsorption systems was the rapid increase in adsorption during the start of the adsorption process which was attributed to the presence of many vacant sites being available for adsorption to take place. The dye adsorption slowed down to a plateau which was due to saturation of adsorption sites and reaching the equilibrium of the adsorption process. Time duration of 120 min was sufficient for WL-AB25 system to attain equilibrium, while 180 min was sufficient for both CP-AB25 and TP-AB25 systems.

Three most commonly used kinetics models (pseudofirst-order (Lagergren 1898), pseudo-second-order (Ho and McKay 1999) and intraparticle diffusion (Weber and Morris 1963) models) were used for characterising the kinetics data and their equations are as follows:

Pseudo-first-order: $\log \left(q_{\mathrm{e}}-q_{t}\right)=\log q_{\mathrm{e}}-\frac{t}{2.303} k_{1}$, 

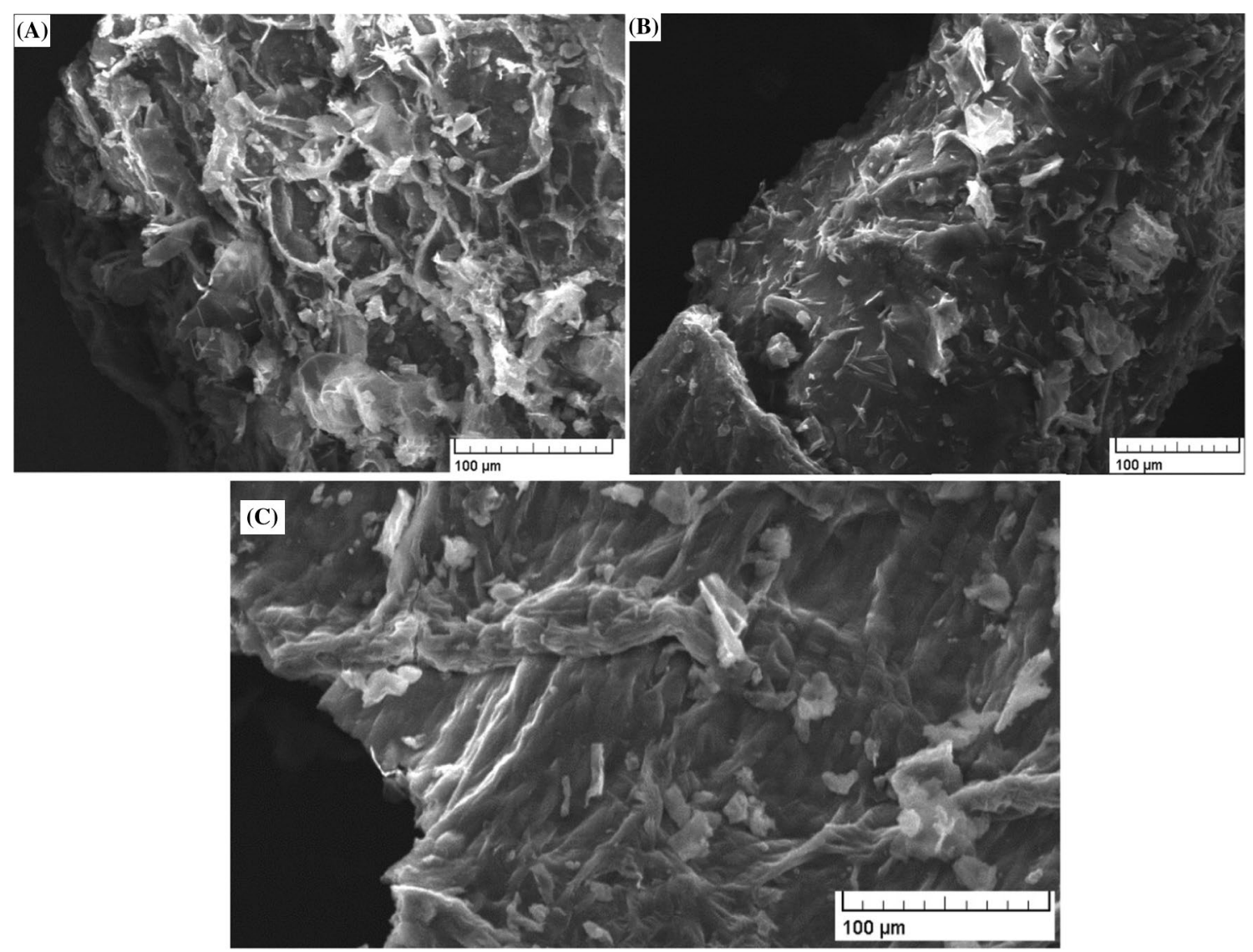

Fig. 2 SEM images displaying the surface morphologies of a WL, b TP and $\mathbf{c}$ CP at $\times 500$ magnification

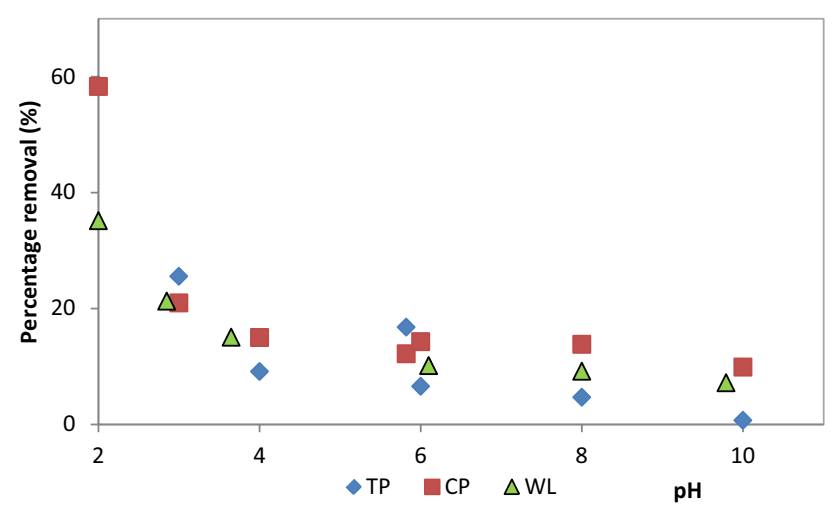

Fig. 3 The effect of $\mathrm{pH}$ on the removal of AB25 using WL, CP and TP

Pseudo-second-order: $\frac{t}{q_{t}}=\frac{1}{q_{\mathrm{e}}^{2} k_{2}}+\frac{t}{q_{\mathrm{e}}}$,

Intraparticle diffusion: $q_{t}=k_{3} t^{1 / 2}+C$,

where $q_{t}$ is the amount of adsorbate adsorbed per gram of adsorbent $\left(\mathrm{mg} \mathrm{g}^{-1}\right)$ at time $t(\min ), k_{1}$ is the pseudo-first-order rate constant $\left(\mathrm{min}^{-1}\right), k_{2}$ is pseudo-second-order rate constant $\left(\mathrm{g} \mathrm{mg}^{-1} \mathrm{~min}^{-1}\right), k_{3}$ is the intraparticle diffusion rate constant $\left(\mathrm{mg} \mathrm{g}^{-1} \mathrm{~min}^{-1 / 2}\right)$ and $C$ is the intercept. The parameters of the pseudo-first-order, pseudosecond-order and intraparticle diffusion models were obtained from the linear plots of $\ln \left(q_{\mathrm{e}}-q_{t}\right)$ vs $t, \frac{t}{q_{t}}$ vs $t$ and $q_{t}$ vs $t^{1 / 2}$, respectively.

The kinetics parameters for all adsorbents are summarised in Table 2. The values of $R^{2}$ were highest for pseudo-second-order model for all three adsorbents when compared to pseudo-first-order which indicates that the pseudo-second-order model was the most suitable to describe the kinetics data. This was reinforced by the lower values of the error functions $\chi^{2}$ and EABS for pseudo-second-order model and also the agreement between the values of $q_{\mathrm{e}, \exp }$ and $q_{\mathrm{e}, \mathrm{cal}}$.

According to Liu (2008), a pseudo-second-order kinetics implies that the adsorption rate follows a second-order rate law with respect to the adsorbent's surface adsorption sites instead of the adsorbate in bulk solution. The poor fitting of pseudo-first-order model is due to it not being a true order equation but rather an approximate solution to 

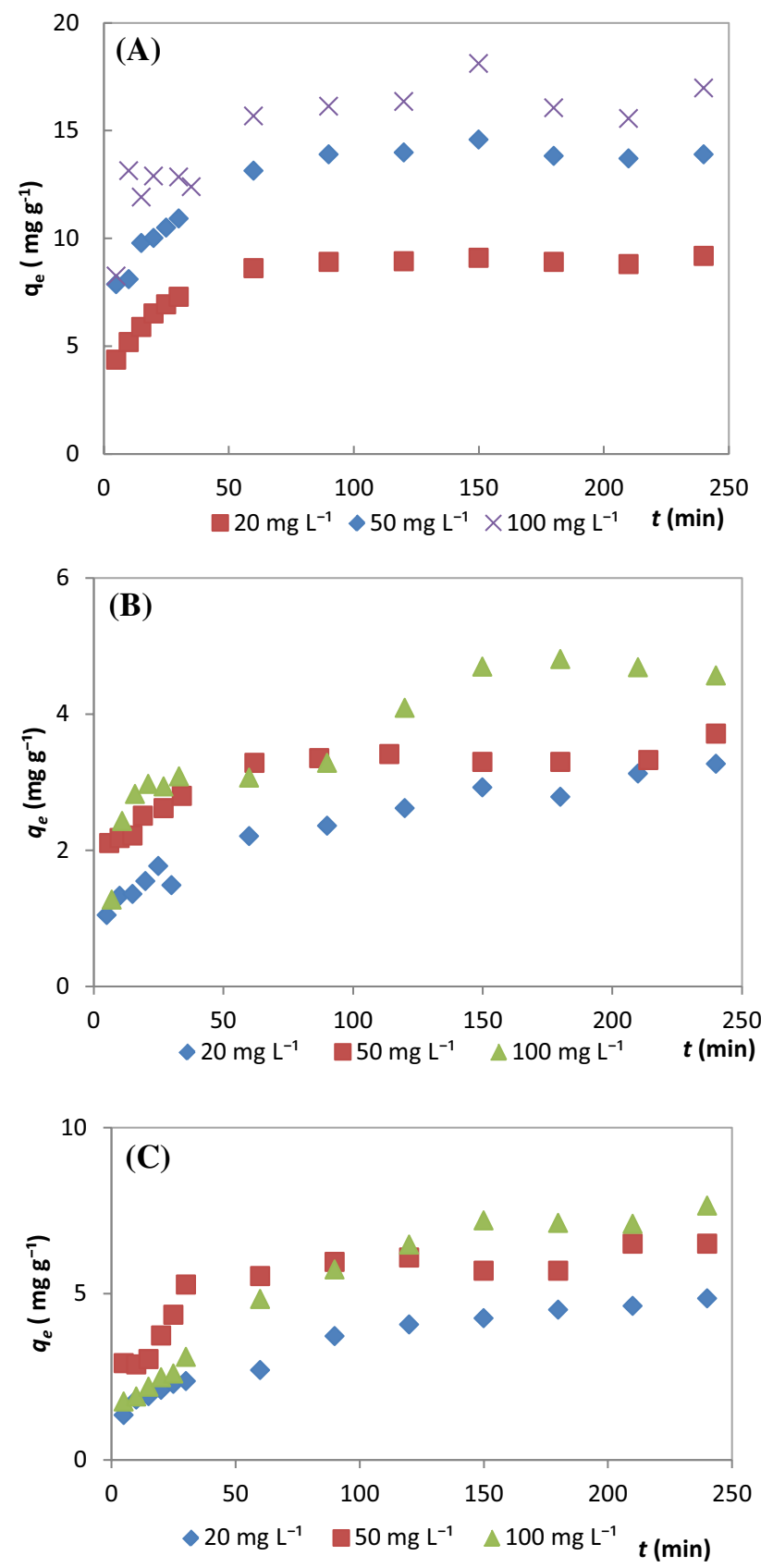

Fig. 4 The adsorption of AB25 as function of time by a WL, b TP and $\mathbf{c} \mathrm{CP}$

the first-order rate mechanism. The reason being the number of sites available does not equate to $q_{\mathrm{e}}$ of the pseudofirst-order model, and also the parameter of $\log q_{\mathrm{e}}$ often differs from the intercept of the plot of $\left(\log q_{\mathrm{e}}-q_{t}\right)$ vs $t$ (Eq. 9) (Aharoni and Sparks 1991).

The diffusion mechanism of the adsorption process is characterised using the intraparticle diffusion model because the pseudo-first and pseudo-second-order models are not applicable. The diffusion process can generally be categorised into three phases, which are the initial fast external diffusion, surface adsorption (intraparticle diffusion) and lastly the equilibrium phase. By fitting the kinetics data into the intraparticle diffusion model, the rate-limiting phase of the adsorption process can be determined. According to the intraparticle diffusion model, if the linear plot of $q_{t}$ vs $t^{1 / 2}$ crossed the origins, then the intraparticle diffusion is the rate-limiting step. As seen in Table 2, all the values of the intercepts are not zero, this indicates that the rate-limiting step was not intraparticle diffusion and other mechanism may have been involved. This observation is very common and has been reported in the removal of hazardous dyes (malachite green and rhodamine B) using water fern (Kooh et al. 2016d, e), and also in the adsorption of methyl violet 2B using soya waste (Kooh et al. 2016c).

\section{Effect of initial dye concentration and isotherm study}

The effect of varying the initial dye concentration on the removal of AB25 onto the adsorbents is shown in Fig. 5. Both WL and CP showed increase in dye uptake as the concentration increased while TP only showed an increase up to $200 \mathrm{mg} \mathrm{L}^{-1}$ before the dye uptake decreased. The increase in dye concentration provided enough force for the mass transfer to occur from the bulk solution and, therefore, an increase in the dye uptake was observed. TP, however, displayed different trend from the other adsorbents whereby the dye uptake decreased after $200 \mathrm{mg} \mathrm{L}^{-1}$. This might be due to the low affinity of TP towards AB25 and although both TP and CP are both of the same genus, their affinities toward AB25 may differ as the peels are made up of different chemical compositions.

The adsorption data were characterised using three isotherm models: Langmuir (Langmuir 1916), Freundlich (Freundlich 1906) and Dubinin-Radushkevich (D-R) (Dubinin and Radushkevich 1947) as follow:

Langmuir: $\frac{C_{\mathrm{e}}}{q_{\mathrm{e}}}=\frac{1}{k_{\mathrm{L}} q_{\mathrm{m}}}+\frac{C_{\mathrm{e}}}{q_{\mathrm{m}}}$,

Freundlich: $\ln q_{\mathrm{e}}=\frac{1}{n_{\mathrm{F}}} \ln C_{\mathrm{e}}+\ln k_{\mathrm{F}}$,

$\mathrm{D}-\mathrm{R}: \ln q_{\mathrm{e}}=\ln q_{\mathrm{m}}-k_{\mathrm{DR}}^{2} \varepsilon^{2}$,

$\varepsilon=R T \ln \left[1+\frac{1}{C_{\mathrm{e}}}\right]$

where $q_{\mathrm{m}}$ is the maximum adsorption capacity of the adsorbent $\left(\mathrm{mg} \mathrm{g}^{-1}\right), k_{\mathrm{L}}$ is the Langmuir adsorption constant $\left(\mathrm{L} \mathrm{mg}^{-1}\right), k_{\mathrm{F}}\left(\mathrm{mg}^{1-1 / n} \mathrm{~L}^{1 / n} \mathrm{~g}^{-1}\right)$ is the adsorption capacity of the adsorbent, $n_{\mathrm{F}}$ is the Freundlich constant where adsorption 
Table 2 Summary of the kinetic parameters

\begin{tabular}{|c|c|c|c|c|c|c|c|c|c|}
\hline \multirow{2}{*}{$\begin{array}{l}\text { Absorbent } \\
C_{\mathrm{i}}\left(\mathrm{mg} \mathrm{L}^{-1}\right)\end{array}$} & \multicolumn{3}{|l|}{ WL } & \multicolumn{3}{|l|}{ TP } & \multicolumn{3}{|l|}{$\mathrm{CP}$} \\
\hline & 20 & 50 & 100 & 20 & 50 & 100 & 20 & 50 & 100 \\
\hline \multicolumn{10}{|l|}{ Pseudo-first order } \\
\hline$q_{\mathrm{e}, \mathrm{cal}}\left(\mathrm{mg} \mathrm{g}^{-1}\right)$ & 3.5 & 5.1 & 5.6 & 2.3 & 0.9 & 5.1 & 3.7 & 2.6 & 5.6 \\
\hline$q_{\mathrm{e}, \exp }\left(\mathrm{mg} \mathrm{g}^{-1}\right)$ & 9.1 & 14.2 & 17.5 & 3.3 & 3.5 & 5.6 & 4.9 & 6.5 & 7.4 \\
\hline$k_{1}$ & 0.019 & 0.017 & 0.009 & 0.011 & 0.010 & 0.010 & 0.013 & 0.009 & 0.012 \\
\hline$R^{2}$ & 0.911 & 0.868 & 0.781 & 0.948 & 0.501 & 0.863 & 0.991 & 0.560 & 0.931 \\
\hline$\chi^{2}$ & 46 & 75 & 108 & 7 & 24 & 3 & 7 & 36 & 10 \\
\hline EABS & 63 & 96 & 127 & 13 & 27 & 7 & 15 & 45 & 21 \\
\hline \multicolumn{10}{|c|}{ Pseudo-second order } \\
\hline$q_{\mathrm{e}, \mathrm{cal}}\left(\mathrm{mg} \mathrm{g}^{-1}\right)$ & 9.4 & 14.6 & 17.1 & 3.5 & 3.5 & 11.3 & 5.3 & 6.4 & 8.1 \\
\hline$q_{\mathrm{e}, \exp }\left(\mathrm{mg} \mathrm{g}^{-1}\right)$ & 9.1 & 14.2 & 17.5 & 3.3 & 3.5 & 5.6 & 4.9 & 6.5 & 7.4 \\
\hline$k_{2}$ & 0.013 & 0.009 & 0.008 & 0.010 & 0.051 & 0.0003 & 0.006 & 0.014 & 0.003 \\
\hline$R^{2}$ & 0.999 & 0.999 & 0.996 & 0.980 & 0.998 & 0.267 & 0.984 & 0.991 & 0.991 \\
\hline$\chi^{2}$ & 4 & 8 & 7 & 3 & 2 & 4 & 5 & 4 & 4 \\
\hline EABS & 14 & 23 & 24 & 7 & 5 & 8 & 11 & 10 & 14 \\
\hline \multicolumn{10}{|c|}{ Intraparticle diffusion } \\
\hline$k_{3}$ & 0.810 & 0.905 & 0.993 & 0.176 & 0.183 & 0.386 & 0.323 & 0.582 & 0.526 \\
\hline$C$ & 2.5 & 5.8 & 7.7 & 0.7 & 1.7 & -0.5 & 0.7 & 1.2 & 0.5 \\
\hline$R^{2}$ & 0.980 & 0.954 & 0.627 & 0.925 & 0.943 & 0.856 & 0.950 & 0.891 & 0.946 \\
\hline
\end{tabular}

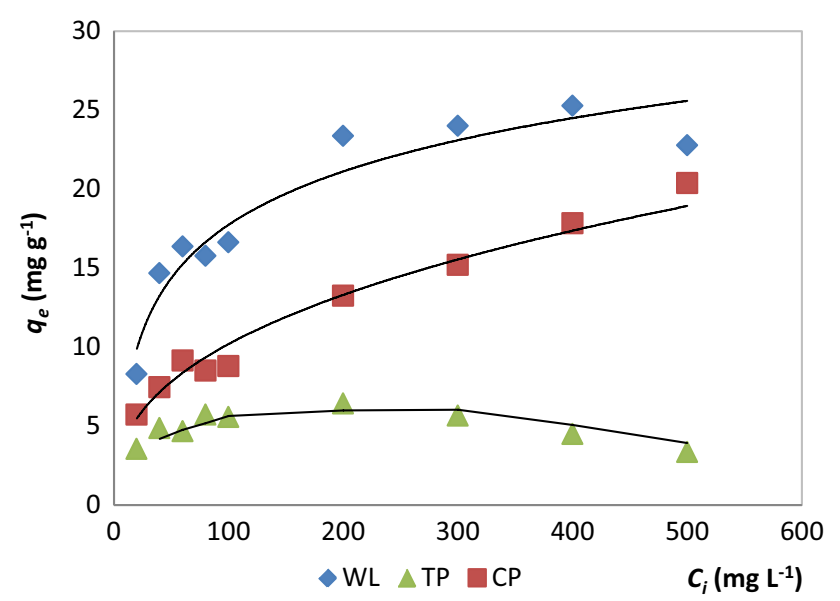

Fig. 5 The effect of AB25 concentration on the adsorption process of WL, TP and CP

process is considered favourable if $1<n_{\mathrm{F}}<10, k_{\mathrm{DR}}$ is a $\mathrm{D}-\mathrm{R}$ constant $\left(\mathrm{mol}^{2} \mathrm{~kJ}^{-2}\right), \varepsilon$ is the D-R isotherm constant which is also known as the Polanyi potential, $R$ is the gas constant $\left(8.314 \times 10^{-3} \mathrm{~kJ} \mathrm{~mol}^{-1} \mathrm{~K}^{-1}\right)$ and $T$ is temperature $(\mathrm{K})$.

The Langmuir model assumes a maximum adsorption resulting in a monolayer film whereby once an adsorption site is occupied it will not be available for another adsorbate. The favourability of the adsorption process can be assessed by a dimensionless constant, separation factor $\left(R_{\mathrm{L}}\right)$, which is expressed as
$R_{\mathrm{L}}=\frac{1}{\left(1+k_{\mathrm{L}} C_{\mathrm{o}}\right)}$,

where $C_{\mathrm{o}}\left(\mathrm{mg} \mathrm{L}^{-1}\right)$ is the highest initial dye concentration.

The value of $R_{\mathrm{L}}$ indicates if the isotherm is unfavourable $\left(R_{\mathrm{L}}>1\right)$, favourable $\left(0<R_{\mathrm{L}}<1\right)$, linear $\left(R_{\mathrm{L}}=1\right)$, or irreversible $\left(R_{\mathrm{L}}=0\right)$.

The Freundlich model is another commonly used isotherm model, and if applicable, would assume formation of multilayer of adsorbates on adsorbent's surface, and the $\mathrm{D}-\mathrm{R}$ isotherm also assumes heterogeneous surface of the adsorbent and is temperature dependent. D-R isotherm is also used to determine the thermodynamic nature of the adsorption by estimating the mean free energy of the sorption per molecule of adsorbate, $E\left(\mathrm{~kJ} \mathrm{~mol}^{-1}\right)$, which is expressed as

$E=\frac{1}{\sqrt{2 k_{\mathrm{DR}}}}$.

The linear plots of $C_{\mathrm{e}} / q_{\mathrm{e}}$ vs $C_{\mathrm{e}}, \ln q_{\mathrm{e}}$ vs $\ln C_{\mathrm{e}}$, and $\ln q_{\mathrm{e}}$ vs $\varepsilon^{2}$ were used for calculating the parameters for the Langmuir, Freundlich and D-R isotherm models, respectively.

Table 3 summarises the isotherm models' parameters for the adsorption of AB25 by WL, TP and CP. The Langmuir, Freundlich and D-R isotherm models are compared with each other to determine which model is suitable to describe the adsorption process of AB25 onto the adsorbents. Between the three models, the Langmuir possessed the highest $R^{2}$ values for TP and WL while the Freundlich 
Table 3 Parameters of the Langmuir, Freundlich and D-R isotherm models

\begin{tabular}{lccc}
\hline$T\left({ }^{\circ} \mathrm{C}\right)$ & $\mathrm{WL}$ & $\mathrm{TP}$ & $\mathrm{CP}$ \\
\hline Langmuir isotherm & & & \\
$q_{\mathrm{m}}\left(\mathrm{mg} \mathrm{g}^{-1}\right)$ & 24.5 & 10.5 & 21.2 \\
$k_{\mathrm{L}}$ & 0.070 & 0.015 & 0.013 \\
$R_{\mathrm{L}}$ & 0.027 & 0.104 & 0.121 \\
$R^{2}$ & 0.992 & 0.685 & 0.963 \\
$\chi^{2}$ & 4.4 & 5.4 & 2.7 \\
EABS & 19.2 & 16.1 & 13.1 \\
Freundlich isotherm & & & \\
$K_{\mathrm{F}}\left(\mathrm{mg}^{1-1 / n} \mathrm{~L}^{1 / n} \mathrm{~g}^{-1}\right)$ & 7.6 & 1.6 & 2.5 \\
$n_{\mathrm{F}}$ & 5.0 & 3.5 & 3.1 \\
$R^{2}$ & 0.906 & 0.654 & 0.972 \\
$\chi^{2}$ & 1.6 & 5.0 & 1.2 \\
$\mathrm{EABS}^{2}$ & 14.0 & 15.1 & 8.6 \\
Dubinin-Radushkevich isotherm & & \\
$q_{\mathrm{m}}\left(\mathrm{mg} \mathrm{g}^{-1}\right)$ & 19.7 & 7.2 & 12.1 \\
$k_{\mathrm{DR}}\left(\mathrm{mol}^{2} \mathrm{~kJ}^{-2}\right)$ & 1.8 & 25.4 & 14.7 \\
$E\left(\mathrm{~kJ} \mathrm{~mol}^{-1}\right)$ & 0.521 & 0.140 & 0.184 \\
$R^{2}$ & 0.691 & 0.386 & 0.448 \\
$\chi^{2}$ & 21.4 & 7.2 & 10.2 \\
EABS $^{2}$ & 41.0 & 18.5 & 30.1 \\
\hline
\end{tabular}

model has the highest $R^{2}$ value for CP. In terms of error analyses, however, the Freundlich model showed the lowest value amongst the isotherm models. Hence, the adsorption process fitted to both the Langmuir and Freundlich models which can be used for describing the adsorption process.

Compared to $\mathrm{CP}$ and $\mathrm{WL}$, TP has lower $R^{2}$ values $(<0.700)$ for all of isotherm models which showed the incompatibility of these models in describing the adsorption of AB25 onto TP probably due to their low affinity for each other.

The $q_{\mathrm{m}}$ of the WL, TP and CP are 24.5, 10.5, $21.2 \mathrm{mg} \mathrm{g}^{-1}$, respectively, which are of similar levels with other adsorbents that were reported in the literature: diatomite (21.4) (Badii et al. 2010) and wood dust (24.4 $\mathrm{mg} \mathrm{g}^{-1}$ ) (Hanafiah et al. 2012), but lower than soya bean waste $\left(38.5 \mathrm{mg} \mathrm{g}^{-1}\right)$ (Dahri et al. 2016) and water fern $\left(50.5 \mathrm{mg} \mathrm{g}^{-1}\right.$ ) (Dahri et al. 2016).

\section{Thermodynamics studies}

The thermodynamics parameters were investigated for temperatures ranging from 25 to $70{ }^{\circ} \mathrm{C}$. All the three adsorbents (WL, CP, TP) displayed $\Delta G^{\circ}$ that became more negative as the temperature increased, and this indicates the spontaneity of the adsorbent-adsorbate systems. The $\Delta H^{\circ}$ for WL, CP and TP were determined to be $20.3,15.2$ and $12.4 \mathrm{~kJ} \mathrm{~mol}^{-1}$, respectively, where these positive values indicate these
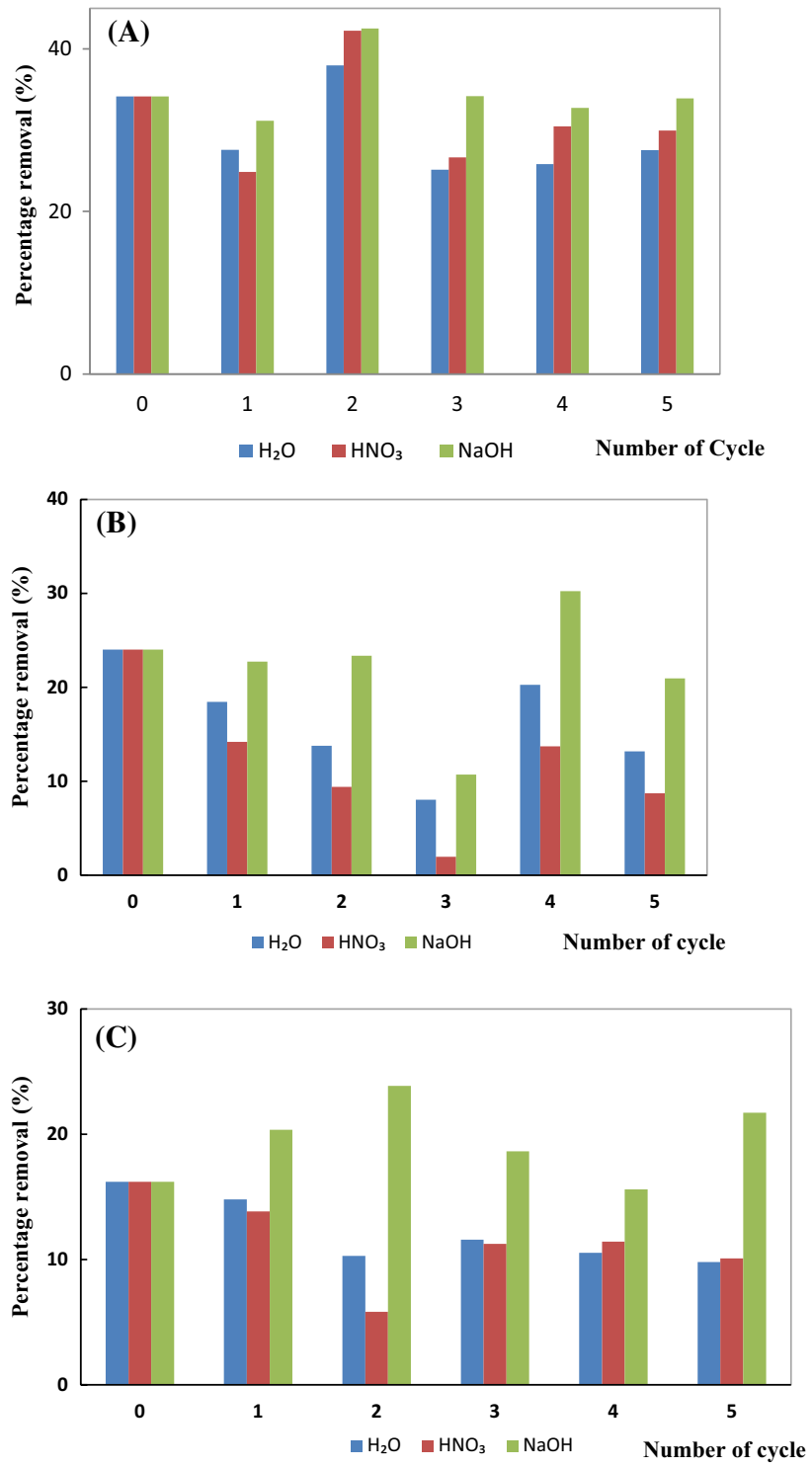

Fig. 6 Regeneration experiment of a WL, b TP and $\mathbf{c}$ CP

adsorption systems were endothermic in nature where heat was gained from the surrounding. $\Delta S^{\circ}$ for $\mathrm{WL}, \mathrm{CP}$ and TP was determined to be $-75,42$ and $32 \mathrm{~J} \mathrm{~mol}^{-1} \mathrm{~K}^{-1}$.

\section{Regeneration experiment}

Spent adsorbents contain hazardous dye substances which should be disposed properly by incineration. Dumping to landfill is not a proper way of disposing hazardous waste as leaching of the dye may occur. However, incineration also has many disadvantages, as it may cost more due to fuel needed for burning, and hazardous gas being released to the environment. Regeneration experiment in this study investigated an alternative route to direct disposal of the spent adsorbent. It is perceived that regeneration of spent 
adsorbent may further reduce the total cost of treatment by adsorption. The regeneration experiments' data are summarised in Fig. 6. For WL, it can be observed that all the three solvents' washing successfully maintained the dye adsorption close to the original level. For CP and TP, there were slight reductions in dye adsorption for every successive cycle for water and acid wash; however, improvement was observed for basic wash. This behaviour may be due to the removal of low molecular fats, lignin and other plant materials with uncovered functional groups that may have interacted with the adsorbates. Investigations on the improvement in dye adsorption by basic wash have been reported in few of our previous works (Dahri et al. 2014; Kooh et al. 2016d).

\section{Conclusions}

The optimal conditions of the adsorption of $\mathrm{AB} 25$ by WL, $\mathrm{TP}$ and $\mathrm{CP}$ were $2 \mathrm{~h}$ of contact time at $\mathrm{pH} 2$. FTIR analysis indicated both the $\mathrm{OH}$ and $\mathrm{NH}$ groups might be involved in the adsorption of the dye on the adsorbents' surfaces. $\mathrm{CP}$ and WL's experimental data can be described using the Langmuir, Freundlich and pseudo-second-order models. TP has the lowest affinity towards AB25 resulting in incompatibility with the isotherm models. The spent adsorbents can be regenerated using $0.1 \mathrm{M} \mathrm{NaOH}$.

Acknowledgements The authors are grateful to the Government of Brunei Darussalam and the Universiti Brunei Darussalam for their support. The authors expressed their gratitude to the Centre for Advanced Material and Energy Sciences (CAMES) of Universiti Brunei Darussalam for their generosity in the usage of XRF machine.

\section{Compliance with ethical standards}

Conflict of interest All authors declare no conflict of interest.

Open Access This article is distributed under the terms of the Creative Commons Attribution 4.0 International License (http://creativeco mmons.org/licenses/by/4.0/), which permits unrestricted use, distribution, and reproduction in any medium, provided you give appropriate credit to the original author(s) and the source, provide a link to the Creative Commons license, and indicate if changes were made.

\section{References}

Aharoni C, Sparks DL (1991) Kinetics of soil chemical reactions-a theoretical treatment. In: Sparks DL, Suarez DL (eds) Rates of soil chemical processes. Soil Science Society of America, Madison, pp 1-18

Badii K, Ardejani FD, Saberi MA, Limaee NY, Shafaei S (2010) Adsorption of acid blue 25 dye on diatomite in aqueous solutions. Indian J Chem Technol 17:7-16

Crini G (2006) Non-conventional low-cost adsorbents for dye removal: a review. Biores Technol 97:1061-1085
Dahri MK, Kooh MRR, Lim LBL (2014) Water remediation using low cost adsorbent walnut shell for removal of malachite green: equilibrium, kinetics, thermodynamic and regeneration studies. J Environ Chem Eng 2:1434-1444

Dahri MK, Kooh MRR, Lim LBL (2016) Adsorption of toxic methyl violet 2B dye from aqueous solution using Artocarpus heterophyllus (Jackfruit) seed as an adsorbent. Am Chem Sci J 15:1-12

Dubinin MM, Radushkevich LV (1947) Equation of the characteristic curve of activated charcoal. Proc Acad Sci 55:327

Freundlich HMF (1906) Over the adsorption in solution. J Phys Chem $57: 385-471$

Fu Y, Viraraghavan T (2001) Fungal decolorization of dye wastewaters: a review. Biores Technol 79:251-262

Hanafiah MAKM, Ngah WSW, Zolkafly SH, Teong LC, Majid ZAA (2012) Acid blue 25 adsorption on base treated Shorea dasyphylla sawdust: kinetic, isotherm, thermodynamic and spectroscopic analysis. J Environ Sci 24:261-268

Ho YS, McKay G (1999) Pseudo-second order model for sorption processes. Process Biochem 34:451-465

Kooh MRR, Dahri MK, Lim LBL (2016a) Jackfruit seed as a sustainable adsorbent for the removal of Rhodamine B dye. J Environ Biotechnol Res 4:7-16

Kooh MRR, Dahri MK, Lim LBL (2016b) The removal of rhodamine B dye from aqueous solution using Casuarina equisetifolia needles as adsorbent. Cogent Environ Sci 2:1140553

Kooh MRR, Dahri MK, Lim LBL, Lim LH, Malik OA (2016c) Batch adsorption studies of the removal of methyl violet $2 \mathrm{~B}$ by soya bean waste: isotherm, kinetics and artificial neural network modelling. Environ Earth Sci 75:783

Kooh MRR, Lim LBL, Lim LH, Bandara JMRS (2016d) Batch adsorption studies on the removal of malachite green from water by chemically modified Azolla pinnata. Desalin Water Treat 57:14632-14646

Kooh MRR, Lim LBL, Lim LH, Dahri MK (2016e) Separation of toxic rhodamine B from aqueous solution using an efficient low-cost material, Azolla pinnata, by adsorption method. Environ Monit Assess 188:1-15

Kooh MRR, Dahri MK, Lim LBL (2017a) Removal of methyl violet 2B dye from aqueous solution using Nepenthes rafflesiana pitcher and leaves. Appl Water Sci 7:3859-3868

Kooh MRR, Dahri MK, Lim LBL (2017b) Removal of the methyl violet $2 \mathrm{~B}$ dye from aqueous solution using sustainable adsorbent Artocarpus odoratissimus stem axis. Appl Water Sci 7:3573-3581

Lagergren S (1898) Zur Theorie der Sogenannten Adsorption gel Ster Stoffe. K Sven Vetenskapsakad Handl 24:1-39

Langmuir I (1916) The constitution and fundamental properties of solids and liquids. J Am Chem Soc 38:2221-2295

Lim LBL, Priyantha N, Tennakoon DTB, Dahri MK (2012) Biosorption of cadmium(II) and copper(II) ions from aqueous solution by core of Artocarpus odoratissimus. Environ Sci Pollut Res Int 19:3250-3256

Lim LBL, Priyantha N, Hei Ing C, Khairud Dahri M, Tennakoon DTB, Zehra T, Suklueng M (2015) Artocarpus odoratissimus skin as a potential low-cost biosorbent for the removal of methylene blue and methyl violet 2B. Desalin Water Treat 53:964-975

Lim LBL, Priyantha N, Chan CM, Matassan D, Chieng HI, Kooh MRR (2016) Investigation of the sorption characteristics of water lettuce (WL) as a potential low-cost biosorbent for the removal of methyl violet 2B. Desalin Water Treat 57:8319-8329

Lim LBL, Priyantha N, Tennakoon DTB, Chieng HI, Dahri MK, Suklueng M (2017) Breadnut peel as a highly effective low-cost biosorbent for methylene blue: equilibrium, thermodynamic and kinetic studies. Arab J Chem 10(Suppl 2):S3216-S3228

Liu Y (2008) New insights into pseudo-second-order kinetic equation for adsorption. Colloids Surf A Physicochem Eng Asp 320:275-278 
Pavia DL, Lampman GM, Kriz GS (1996) Introduction to spectroscopy, 2nd edn. Saunders College Publishing, San Luis Obispo

Pearce C, Lloyd J, Guthrie J (2003) The removal of colour from textile wastewater using whole bacterial cells: a review. Dyes Pigments 58:179-196

Priyantha N, Lim LBL, Tennakoon DTB, Mansor NHM, Dahri MK, Chieng HI (2013) Breadfruit (Artocarpus altilis) waste for bioremediation of $\mathrm{Cu}$ (II) and $\mathrm{Cd}(\mathrm{II})$ ions from aqueous medium. Ceylon J Sci (Phys Sci) 17:19-29

Robinson T, McMullan G, Marchant R, Nigam P (2001) Remediation of dyes in textile effluent: a critical review on current treatment technologies with a proposed alternative. Bioresour Technol 77:247-255

Tang YP, Linda BLL, Franz LW (2013) Proximate analysis of Artocarpus odoratissimus (Tarap) in Brunei Darussalam. Int Food Res J 20:409-415
Weber W, Morris J (1963) Kinetics of adsorption on carbon from solution. J Sanit Eng Div 89:31-60

Zehra T, Priyantha N, Lim LBL, Iqbal E (2015) Sorption characteristics of peat of Brunei Darussalam V: removal of Congo red dye from aqueous solution by peat. Desalin Water Treat 54:2592-2600

Publisher's Note Springer Nature remains neutral with regard to jurisdictional claims in published maps and institutional affiliations. 